\title{
Characteristics of adolescents who visit the emergency department following suicide attempts: comparison study between adolescents and adults
}

Jinhee Lee ${ }^{1 \dagger}$, Yeon Sik Bang ${ }^{1 \dagger}$, Seongho Min ${ }^{1}$, Joung-Sook Ahn ${ }^{1}$, Hyun Kim², Yong-Sung Cha², In-Suk Park ${ }^{3}$ and Min-Hyuk Kim ${ }^{1 *}$

\begin{abstract}
Background: The purpose of this study was to identify the demographic and clinical characteristics of suicide attempts in adolescents who visit the emergency department compared to those of adults.

Methods: This study included 149 children under the age of 18, and 1427 people in the age of 19-65 who came to the emergency department with suicide attempt from 2009 to 2015. We compare sociodemographic, clinical, and suicide attempt-related characteristics through Chi-square test and logistic regression analysis to evaluate the difference between two groups.

Results: In adolescents, suicide attempters had more number of previous suicide attempt history than adults. Adolescents used more non-lethal method such as poisoning of over the counter drugs and had about 5 times higher odds ratio in suicide attempts with analgesics. The motivation of suicide attempt among adolescents was more related with interpersonal problems but less with financial or illness-related problems. The intention of suicide attempt in adolescents was less serious and lethal compared to adults.

Conclusion: Suicide attempts among adolescents had showed different from adults in method, motivation and intention. Considering the characteristics of suicide attempt among adolescent, it is necessary to keep close attention to adolescent's suicide attempters and develop the customized intervention program to prevent the suicide attempt in this groups.
\end{abstract}

\section{Background}

Suicide is one of the most important issues related to mental health, both personally and socially. Every year close to 800,000 people died from suicide, and suicide attempt rate are about 10 times higher than suicide rate $[1,2]$. According to OECD's survey results, in South Korea in the year 2013, 28.7 people per 100,000 population attempted suicide and recorded the 1st place with more than twice the suicide rate of other OECD countries [3, 4]. This serious suicide problem applies not only to adults but also to adolescents. The most common

\footnotetext{
* Correspondence: mhkim09@yonsei.ac.kr

${ }^{1}$ Department of Psychiatry, Yonsei University Wonju College of Medicine, 20 Ilsan-ro, Wonju 26426, Republic of Korea

Full list of author information is available at the end of the article
}

cause of death among teenagers in Korea in 2016 is suicide [5]. Unlike other OECD countries, the death rate of adolescents' suicides in Korea has shown an increasing trend [6].

Suicide attempts are caused by complex factors such as genetic, environmental, cultural and psychiatric factors [7]. Adolescents' suicide attempts differ from those of adults, because of their physical changes and their varied emotional experiences in their environment. According to previous studies, adolescents attempted suicide more impulsively than adults and opted for less fatal methods of attempts [8]. Suicide attempters among adolescents had fewer number of psychiatric diagnoses [9] and their mental disorders are easily less identified or diagnosed by professional [10]. Also they had fewer

(c) The Author(s). 2019 Open Access This article is distributed under the terms of the Creative Commons Attribution 4.0 International License (http://creativecommons.org/licenses/by/4.0/), which permits unrestricted use, distribution, and reproduction in any medium, provided you give appropriate credit to the original author(s) and the source, provide a link to the Creative Commons license, and indicate if changes were made. The Creative Commons Public Domain Dedication waiver (http://creativecommons.org/publicdomain/zero/1.0/) applies to the data made available in this article, unless otherwise stated. 
suicidal motivations due to economic problems and physical illnesses, and used more over the counter drug poisoning as a suicide attempt than adults [11].

Although previous studies have described risk factors for suicide and suicidal behavior in adolescents [12-14], very few studies have directly compared demographic and clinical features with adults. In addition, most of these studies were carried out with patients hospitalized after attempted suicide. Therefore, the study conducted on patients visiting the emergency department (ED) is very limited. Considering that the proportion of patients admitted to medical facilities due to attempted suicide is small, the results of previous researches are limited in representing the characteristics of the entire suicide attempt [15].

Since suicide attempt in adolescents is a risk factor for subsequent retries and suicide death, identifying the distinct characteristics of patients who visited an ED has clinical significance in establishing prevention strategies for adolescents' suicides. We hypothesized that unique characteristics may have influenced suicidal behavior in adolescent group and identification of the characteristics of suicide attempters among adolescents will help establish efficient preventive strategies (i.e., specific target, points of access, methods, and intensity of care). In the context, the purpose of this study was to identify the demographic and clinical characteristics of suicide attempts in adolescents compared with those of adults who visited the ED.

\section{Methods}

\section{Study subject}

The subjects were under 65 years old, visited in ED in Wonju city, South Korea, from March 01, 2009 to December 31, 2015.

Wonju is a city with a population of 330,000 and approximately $10 \%$ of the population is engaged in agriculture. The ED is the only regional emergency medical center that covers the city, neighboring small towns and rural areas. Most of suicide attempters visit the ER for medical care.

For comparison, adolescents and adults were divided into two groups: adolescents between 12 and 18 years of age and adults between 19 and 65 years of age. Patients older than 65 years were defined as elderly and were excluded from this study, because they were thought to have characteristics distinguished from adults aged 65 and under [16]. For the suicide reattempters, we used the data collected at the first ED visit during the study period.

The definition of suicide attempt was based on the WHO criteria [17], as a nonfatal self-directed potentially injurious behavior with any intent to die as a result of the behavior. In this study, we defined 'suicide attempts' as incidents when the patients and caregivers reported obvious intent. Only when the attempters were unable to provide reliable information due to mental confusion or severe physical damages, medical staff confirmed the injuries as possible suicide attempts using clear evidences (i.e., obvious circumstance, witness reports).

\section{Data collection and measurement}

For patients who visited the ED, medical/surgical initial assessment and first aid for injuries were performed. Then psychiatric interviews were conducted by psychiatric residents and research assistants (i.e. trained nurse and social workers). When the attempters were unable to provide reliable information because of mental confusion or severe physical damage, only their caregiver was interviewed. When informant discrepancies arose between them, we relied on the attempters' report, except when they were mentally confused. If emergency surgery is needed due to severe injury, authors confirmed the missing information via consult after hospitalization.

Factors related to suicide attempts were classified as socio-demographic, clinical, and suicide attempt-related characteristics.

\section{Socio-demographic and clinical characteristics}

Socio-demographic characteristics include age, gender, marital status, education level, income, religion. Clinical characteristics include medical illness, psychiatric illness history, psychiatric family history, family history of suicide, previous suicide attempt, current psychiatric treatment, and clinical psychiatric diagnosis. Based on the collected information, the clinician who interviewed patients and caregivers made an estimated-diagnosis by DSM - IV - TR, and two psychiatrists confirmed the diagnosis. The diagnoses were classified into a total of 10 disorder groups; anxiety disorders, somatoform disorder, depressive disorder, bipolar disorder, schizophrenia or other psychotic disorders, substance disorders, mental retardation / learning disorders / developmental disorder, dementia or organic mental disorder, adjustment disorder, personality disorder. If more than 2 diagnoses were made, the diagnosis that had the greatest effect on suicide attempts was set as 1st diagnosis.

\section{Suicide attempt-related characteristics}

Suicide attempt-related characteristics include method, motivation, intention to die, attempts with suicidal plan, sustained suicidal ideation, medical lethality, use of alcohol before the attempt, joint suicide attempts. The method of suicide attempt was divided into 6 groups. (i.e. poisoning, asphyxia by gas, hanging, injury by sharp object, jumping and drowning, others). Also, poisoning was divided into analgesics, psychiatric medication, herbicide and pesticide, and other medications. Multiple 
selections were allowed for the type of medication used. The motivation for suicide attempt was divided into 8 groups (i.e. psychiatric, interpersonal, job-related, economic, illness-related, loss, abuse-related, legal problem). Multiple selections were allowed. The intention to die was classified as one of 'some or little,' 'certain' in consideration of self-report on suicidal intent, objective circumstances, daily life, and methods. The attempts with suicidal plan means attempters had made a specific plan to suicide attempt and suicide attempt had been the consequence of the plan, and the sustained suicidal ideation means the suicide attempters had suicidal ideation consistently after the suicide attempt which have brought the attempters to the hospital. Medical lethality was divided into 'mild to moderate (no damage or mild physical damage)' and 'severe (severe physical damage requiring intensive treatment)' categories, taking into account physical impairment and required treatment intensity. The use of alcohol before the attempt means whether the suicide attempter was under intoxication at the moment of suicide attempt and the joint suicide attempts means that there was one or more co-suicide attempters at the attempted suicide.

Two psychiatrists, two psychiatric residents and research assistants reviewed all registered cases once a week at the case discussions. The members of the discussions reviewed the diagnostic validity of each patient. Also, the missing information from the initial assessment was supplemented by additional information obtained after the ED visit.

Ethical approval for the investigation was obtained from the Research Ethics Committee of Yonsei University Wonju College of Medicine, and waiver of documentation of consent has been approved by the committee.

\section{Statistical analyses}

Pearson's chi - square test was performed to evaluate the difference between socio - demographic factors and suicide - related factors in adolescents and adults. Variables, where expected frequency less than 5 was over $20 \%$ were analyzed with Fisher exact test. Bivariate logistic regression analysis was performed with explanatory variables as independent variables to identify risk factors that could predict adolescent suicide attempts compared with adults. Regression model applied Backward, Wald method.

Furthermore, to compare the characteristics of the variables according to sex, men and women were divided and t-test and bivariate logistic regression analysis were performed in the same manner as described above.

All statistical significance was $p<0.05$ and a two-sided test was used. All analyzes used SPSS version 21.

\section{Results}

Sociodemographic characteristics (Table 1)

A total of 2003 patients visited the ED after suicide attempt from March 2009 to December 2015. Among them, those older than 65 were excluded from the analysis and a total of 1,576 were the subjects of the study. There were 149 children under the age of 18 , and 1,427 people in the age of 19-65. The average age of the two groups was $15.55 \pm 1.60,41.33 \pm 11.798$ $(\mathrm{t}=-76.04, p<0.001)$.

In both groups, there were more women than men, but the rate of women was significantly higher than in adolescents group in the adult group. ( $76.5 \%$ vs $57.4 \%, \times$ $2=20.41, p<0.001)$.

\section{Mental health (Table 1)}

History of suicide attempt prior to index suicide attempt was statistically more significantly higher than that of adults in adolescents. ( $41.5 \%$ vs $29.4 \%, \times 2=9.22, p=$ $0.00)$. There was no difference between the two groups in the presence of religions, family income, psychiatric treatment, family history of suicide, and family history of mental illness. In psychiatric diagnosis, the adolescents group had fewer substance use disorder and more adjustment disorder than the adult group. $(1.3 \%$ vs $11.5 \%, \times 2=14.75, p<0.001 ; 26.2 \%$ vs $16.0 \%, \times 2=9.80$, $p=0.00$, respectively). When analyzing for gender differences, the ratio of adjustment disorders was relatively high $(37.1 \%)$ in male adolescents than male adults, but in females, the diagnosis of adjustment disorders was not different.

\section{Suicide-related indicators (Table 2)}

Alcohol intake before the suicide attempt was lower in adolescents than in adults. $(17.6 \%$ vs $64.7 \%, \times 2=124.10$, $p<0.001) .17 .6 \%$ of adolescents had certain intent to attempted suicide, and $41.1 \%$ of adults had certain intent. $(\times 2=22.71, p<0.001)$. There was no difference between the two groups when comparing pre-planning before the suicide attempt.

In medical lethality, adolescents were mostly mild, with $80.1 \%$. However, Adults tended to attempt suicide in a relatively more lethal manner, which moderate to severe $(49.1 \%)$ accounting for almost half of the cases. $(\times 2=45.37, p<0.001) 5.3 \%$ of adolescents attempted joint suicide, significantly more than $0.9 \%$ of adults $(x$ $2=17.53, p<0.001)$. This tendency was statistically significant for women only $(6.9 \%$ vs $0.9 \%, \times 2=20.24, p<$ 0.001 ). The rate of admission after the suicide attempt was statistically lower than $31.9 \%$ in adults with $23.5 \%$ in adolescents. ( $23.5 \%$ vs $31.9 \%, \times 2=4.43, p=0.03$ ).

As a motive for suicide, adolescents were more likely to attempt suicide due to interpersonal problem and abusive issues than adults. $(79.9 \%$ vs $63.8 \%, \times 2=14.74$, 
Table 1 Socio-demographic and clinical characteristics of subject

\begin{tabular}{|c|c|c|c|c|c|c|}
\hline \multirow[t]{2}{*}{ Variable (missing values) } & \multicolumn{2}{|c|}{$\begin{array}{l}\text { Adolescents } \\
(N=149)\end{array}$} & \multicolumn{2}{|c|}{$\begin{array}{l}\text { Adults } \\
(N=1427)\end{array}$} & \multirow[t]{2}{*}{$\times 2$} & \multirow[t]{2}{*}{$p$-value } \\
\hline & $N$ & $\%$ & $N$ & $\%$ & & \\
\hline \multicolumn{7}{|l|}{ Gender } \\
\hline Male & 35 & 23.5 & 608 & 42.6 & 20.41 & $<0.001$ \\
\hline Female & 114 & 76.5 & 819 & 57.4 & & \\
\hline Religion (102) & 53 & 38.4 & 529 & 39.6 & 0.07 & 0.78 \\
\hline Somatic illness (193) & 13 & 9.6 & 325 & 26.1 & 18.08 & $<0.001$ \\
\hline \multicolumn{7}{|l|}{ Family income $(10,000 \mathrm{~V})(341)$} \\
\hline $0-100$ & 43 & 36.1 & 397 & 35.6 & 5.51 & 0.138 \\
\hline $101-200$ & 27 & 22.7 & 341 & 30.6 & & \\
\hline $201-300$ & 23 & 19.3 & 211 & 18.9 & & \\
\hline $301-$ & 26 & 21.8 & 193 & 15.0 & & \\
\hline History of suicide attempts (63) & 61 & 41.5 & 401 & 29.4 & 9.22 & 0.00 \\
\hline History of psychiatric treatment (159) & 53 & 38.1 & 508 & 39.7 & 0.13 & 0.71 \\
\hline Family history of suicide (123) & 13 & 9.0 & 100 & 7.6 & 0.34 & 0.55 \\
\hline Familial psychiatric illness history (112) & 14 & 9.7 & 159 & 12.0 & 0.67 & 0.41 \\
\hline \multicolumn{7}{|l|}{ Psychiatric diagnosis (449) } \\
\hline Anxiety disorder & 0 & 0.0 & 4 & 0.3 & & 1.00 \\
\hline Somatoform disorder & 0 & 0.0 & 8 & 0.6 & 0.84 & 0.36 \\
\hline Depressive disorder & 54 & 36.2 & 456 & 32.0 & 1.13 & 0.28 \\
\hline Bipolar disorder & 0 & 0.0 & 19 & 1.3 & 2.00 & 0.15 \\
\hline Schizophrenia & 4 & 2.7 & 33 & 2.3 & 0.08 & 0.77 \\
\hline Substance use disorder & 2 & 1.3 & 164 & 11.5 & 14.75 & $<0.001$ \\
\hline Organic mental disorder & 0 & 0.0 & 1 & 0.1 & & 1.00 \\
\hline Adjustment disorder & 39 & 26.2 & 229 & 16.0 & 9.80 & 0.00 \\
\hline Personality disorder & 5 & 3.4 & 36 & 2.5 & 0.36 & 0.54 \\
\hline
\end{tabular}

$p<0.001 ; 5.6 \%$ vs $1.1 \%, \times 2=17.87, p<0.001$, respectively). On the other hand, Motivations due to economic causes $(4.3 \%$ vs $26.0 \%, \times 2=33.08, p<0.001)$ and illnessrelated causes $(1.4 \%$ vs $6.6 \%, \times 2=5.97, p<0.01)$ were lower than adults.

In method of suicide attempt, adolescents used more ways of taking analgesics than adults. (28.9\% vs $3.9 \%, \times$ $2=142.48, p<0.001)$ Psychiatric medications poisoning (30.9\% vs $18.8 \%, \times 2=9.46, p=0.002)$ and pesticide and herbicide poisoning $(20.5 \%$ vs $3.4 \%, \times 2=25.96, p<$ $0.001)$ were less than adults.

\section{Binary logistic regression analysis for factors associated to suicide attempt (Table 3 )}

The adjusted Odds ratio obtained by performing binary logistic regression analysis is shown In Table 3. After adjustment, the factors that have a significant difference between adolescents and adults were the presence of physical illnesses, the history of previous suicide, the alcohol intake prior to suicide attempts, intention to die, lethality of suicide attempts, economic motivation, analgesics poisoning, psychiatric medications poisoning, pesticide and herbicide poisoning, and substance use disorder.

Compared to adults, the OR of past suicide attempt was 2.85 times higher after the correction, and the proportion of alcohol intake was 0.09 times lower. The adjusted OR of intention to die was 0.39 (95\% CI $0.19-$ $0.80, p=0.01)$, the adjusted OR of medical lethality above moderate was 0.45 (95\% CI $0.24-0.86, p=0.01$ ).

In adolescents, the OR of suicide attempts with analgesics as compared to adults was 5.00 (95\% CI 2.30-10.87, $p<0.001)$. In contrast, psychiatric medication was 0.40 (95\% CI $0.21-0.75, p=0.00$ ) and pesticide and herbicide poisoning was 0.13 (95\% CI 0.02-0.49, $p=0.00)$.

For the psychiatric diagnosis, after correction, the adjustment disorder had no significant effect on the difference between two groups. But, in adolescents, the OR of the substance use disorder was found to be much smaller by 0.14 times. (95\% CI $0.01-1.18, p=0.07$ ). 
Table 2 Suicide-related characteristics of subjects

\begin{tabular}{|c|c|c|c|c|c|c|}
\hline & \multicolumn{2}{|c|}{$\begin{array}{l}\text { Adolescents } \\
(N=149)\end{array}$} & \multicolumn{2}{|c|}{$\begin{array}{l}\text { Adults } \\
(N=1427)\end{array}$} & \multirow[t]{2}{*}{$\times 2$} & \multirow[t]{2}{*}{$p$-value } \\
\hline & $N$ & $\%$ & $N$ & $\%$ & & \\
\hline Use of alcohol before the attempt (39) & 26 & 17.6 & 899 & 64.7 & 124.10 & $<0.001$ \\
\hline \multicolumn{7}{|l|}{ Current suicidal ideation (109) } \\
\hline No & 77 & 56.2 & 556 & 41.8 & \multirow[t]{3}{*}{18.86} & \multirow[t]{3}{*}{$<0.001$} \\
\hline Yes & 44 & 32.1 & 399 & 30.0 & & \\
\hline Unknown & 16 & 11.7 & 375 & 28.2 & & \\
\hline Attempts with suicide plan (245) & 25 & 19.1 & 195 & 16.2 & 0.68 & 0.40 \\
\hline \multicolumn{7}{|l|}{ Intention to die (184) } \\
\hline Some or little intention & 89 & 82.4 & 584 & 58.9 & 22.71 & $<0.001$ \\
\hline Certain intention & 19 & 17.6 & 408 & 41.1 & 22.71 & $<0.001$ \\
\hline \multicolumn{7}{|l|}{ Medical lethality (28) } \\
\hline mild & 117 & 80.1 & 714 & 50.9 & 45.37 & $<0.001$ \\
\hline moderate to severe & 29 & 19.9 & 688 & 49.1 & $\begin{array}{l}45.37 \\
17.53\end{array}$ & $\begin{array}{l}<0.001 \\
<0.001\end{array}$ \\
\hline Joint suicide attempts (215) & 7 & 5.3 & 11 & 0.9 & & \\
\hline Admission (299) & 35 & 23.5 & 455 & 31.9 & 4.43 & 0.03 \\
\hline \multicolumn{7}{|l|}{ Motivation of the suicide } \\
\hline Psychiatric (127) & 27 & 24.7 & 323 & 24.7 & 2.13 & 0.14 \\
\hline Interpersonal (85) & 115 & 79.9 & 860 & 63.8 & 14.74 & $<0.001$ \\
\hline Job-related (126) & 21 & 14.6 & 252 & 19.3 & 1.88 & 0.17 \\
\hline Economic (111) & 6 & 4.3 & 344 & 26.0 & 33.08 & $<0.001$ \\
\hline IIIness-related (123) & 2 & 1.4 & 86 & 6.6 & 5.97 & 0.01 \\
\hline Loss of family member (123) & 3 & 2.1 & 34 & 2.6 & 0.11 & 0.73 \\
\hline Abuse-related (125) & 8 & 5.6 & 14 & 1.1 & 17.87 & $<0.001$ \\
\hline Legal problem (129) & 0 & 0.0 & 8 & 0.6 & 0.86 & 0.35 \\
\hline \multicolumn{7}{|l|}{ Method of suicide attempt } \\
\hline Poisoning & 101 & 67.8 & 946 & 66.3 & 0.13 & 0.71 \\
\hline Analgesics & 43 & 28.9 & 56 & 3.9 & 142.48 & $<0.001$ \\
\hline Psychiatric medication & 28 & 18.8 & 441 & 30.9 & 9.46 & 0.00 \\
\hline Pesticide and Herbicide & 5 & 3.4 & 293 & 20.5 & 25.9 & $<0.001$ \\
\hline Other medications & 27 & 18.1 & 266 & 18.6 & 0.02 & 0.87 \\
\hline Asphyxia by gas & 9 & 6.0 & 152 & 10.7 & 3.12 & 0.07 \\
\hline Hanging & 5 & 3.4 & 106 & 7.4 & 3.41 & 0.06 \\
\hline Injury by sharp object & 26 & 17.4 & 171 & 12.0 & 3.68 & 0.05 \\
\hline Jumping and Drowning & 6 & 4.0 & 34 & 2.4 & 1.47 & 0.22 \\
\hline Others & 2 & 1.3 & 18 & 1.3 & 0.00 & 0.93 \\
\hline
\end{tabular}

\section{Discussion}

This is the first study to directly compare the characteristics of suicide attempts in adolescents who visit the ED compared to those of adults. We tried to discover the characteristics of suicide attempts in adolescents, comparing social demographic, clinical, suicide-related factors, for a total of 149 adolescents and 1427 adults under the age of 65 .
Women in both groups were more than men, which was the same as the results of previous studies $[11,18,19]$. The rate of hospitalization was significantly higher in adults. (23.5\% vs $31.9 \%)$. Previous studies have shown a various rate of hospital admissions after suicide attempts. In one study, about $34 \%$ of adolescent suicides attempters were hospitalized [15], and in another study, 26.9\% of attempters were hospitalized [20]. In addition, about one-third of the 
Table 3 Binary logistic regression model of factors associated to suicide attempt

\begin{tabular}{|c|c|c|c|c|}
\hline Variable & OR $(95 \% \mathrm{Cl})$ & $P$ & $\mathrm{aOR}(95 \% \mathrm{Cl})$ & $P$ \\
\hline Gender & $0.41(0.27-0.61)$ & $<0.001$ & & \\
\hline Somatic illness & $0.30(0.16-0.53)$ & $<0.001$ & $0.38(0.17-0.82)$ & 0.01 \\
\hline History of suicide attempts & $1.70(1.20-2.41)$ & 0.00 & $2.85(1.63-4.97)$ & $<0.001$ \\
\hline Use of alcohol before the attempt & $0.11(0.07-0.18)$ & $<0.001$ & $0.09(0.05-0.17)$ & $<0.001$ \\
\hline \multicolumn{5}{|l|}{ Current suicidal ideation } \\
\hline No & & $<0.001$ & & \\
\hline Yes & $0.79(0.53-1.17)$ & 0.25 & & \\
\hline Unknown & $0.30(0.17-0.53)$ & $<0.001$ & & \\
\hline \multicolumn{5}{|l|}{ Intention to die } \\
\hline \multicolumn{5}{|l|}{ Some or little intention } \\
\hline Certain intention & $0.30(0.18-0.50)$ & $<0.001$ & $0.39(0.19-0.80)$ & 0.01 \\
\hline \multicolumn{5}{|l|}{ Medical lethality } \\
\hline \multicolumn{5}{|l|}{ mild } \\
\hline moderate to severe & $0.25(0.16-0.39)$ & $<0.001$ & $0.458(0.24-0.86)$ & 0.01 \\
\hline Joint suicide attempts & $6.14(2.34-16.13)$ & $<0.001$ & & \\
\hline \multicolumn{5}{|l|}{ Motivation of the suicide } \\
\hline Interpersonal & $2.24(1.47-3.42)$ & $<0.001$ & & \\
\hline Economic & $0.12(0.05-0.28)$ & $<0.001$ & $0.19(0.07-0.51)$ & 0.00 \\
\hline Illness-related & $0.20(0.05-0.836)$ & 0.02 & & \\
\hline Abuse-related & $5.52(2.27-13.40)$ & $<0.001$ & & \\
\hline \multicolumn{5}{|l|}{ Method of suicide attempt } \\
\hline Analgesics & $9.93(6.37-15.48)$ & $<0.001$ & $5.00(2.30-10.87)$ & $<0.001$ \\
\hline Psychiatric medications & $0.51(0.33-0.79)$ & 0.00 & $0.40(0.21-0.75)$ & 0.00 \\
\hline Pesticide and Herbicide & $0.13(0.05-0.33)$ & $<0.001$ & $0.11(0.02-0.49)$ & 0.00 \\
\hline \multicolumn{5}{|l|}{ Psychiatric diagnosis } \\
\hline Substance use disorder & $0.10(0.02-0.42)$ & 0.00 & $0.14(0.01-1.18)$ & 0.07 \\
\hline Adjustment disorder & $1.85(1.25-2.74)$ & 0.00 & & \\
\hline Admission at medical institutions & $0.65(0.44-0.97)$ & 0.03 & & \\
\hline
\end{tabular}

patients visiting the ED was hospitalized after attempting regardless of age [19]. Admission rates are influenced by various factors, such as the medical system and management guideline, so it is difficult to directly compare them. In this study, it is estimated that the high medical lethality of suicides in adults is associated with the high admission rates in adults.

At the time of visiting the ED, $41.5 \%$ of the adolescents had a history of suicide attempt, which was significantly higher than adults. The rate of suicide attempts in previous adolescent suicide attempts in the ED was $53.3 \%$ in the UK and $37.9 \%$ in the European multicenter study, similar to those in the present study [21, 22]. In previous studies compared with adults, one study found that adults were more likely to attempt suicide [8], but, other study reported no significant difference [11]. These studies were conducted on inpatients, so the proportion of patients who had a history of attempt is high and difficult to compare with the results of this study. Also, in this study, since adolescents tend to attempt suicide with relatively little intent compared to adults, these pattern of suicide attempts may have been repeated. However, as in adults, adolescents' repeated suicide attempts increase the risk of subsequent suicide re-attempts and are also a factor that increases the likelihood of suicide death [23]. According to previous studies, about $15 \%$ of suicide re-attempts occurred in six months, $13.6-24 \%$ in a year [24-26]. In addition, considering our findings shows that adolescents had little previous psychiatric diagnosis or history of treatment, in reality, psychological assessment and intervention after suicide attempt may not have been properly made. This suggests that it is urgent and important to establish strategies for early 
detection and intervention after the first suicide attempt by adolescents.

In the adolescents group, diagnosis of an adjustment disorder was greater than that of adults, and it was consistent with the results of previous comparison study [8]. Also, 21\% of adolescents in psychological autopsy study conducted in Finland were diagnosed as adjustment disorders, similar to $26 \%$ in this study [27]. However, the difference was significant only in male adolescents. One study showed that female adolescents report more of the symptoms of depressed mood and guilt than male in depressive disorder [28]. It cannot be ruled out that the female adolescents were more likely to have been diagnosed with depressive disorder due to the high level of expression of symptoms, whereas the male adolescents were diagnosed with an adjustment disorder, in the ER where diagnosis is made with limited information. Research using a structured interview tools on more samples should be carried out to identify gender differences in the psychiatric diagnosis of adolescents.

The results of our study show that a majority of adolescents attempt suicide in the context of interpersonal conflicts, whereas a majority of adults attempt suicide in the context of economic problems. These findings are consistent with the earlier studies that have reported interpersonal issues as the most common motivation for adolescents' suicide attempts [7, 11, 18, 21]. Various changes in relationships, emotional instability, and a lack of coping skills in dealing with them may lead adolescents to suicide attempt $[7,29]$. Therefore, it is necessary to provide educations on coping skills for various interpersonal issues and stress management to prevent adolescents' suicide attempt.

Poisoning was the most common method of suicide attempt for both groups. But adults were more likely to try to suicide attempt by overdosing on psychiatric medications or herbicides/pesticides while adolescents were more prone to analgesics. It is consistent with previous studies that adolescents prefer to take analgesics as a way to suicide attempt [8], and there are also reports that legislation regarding package size of analgesics is effective in preventing suicides [30]. This is understandable in terms of availability, as analgesics are easy to get. Another consideration is the high risk of suicide in adolescents already abusing analgesics. The previous study has shown that approximately $4.7 \%$ of adolescent misuse over-the-counter drugs, with higher prevalence of psychiatric illness and suicides than non-users [26]. Because some adolescents who abuse analgesics use them to reduce sleep or anxiety [31], it is possible that the adolescents who used the analgesic drug as a self-medication used it as a way to suicide attempt. This can be seen as similar to using psychiatric drugs in adult suicide attempters. Assessment of risk of suicide might be required in adolescent patients suspected of abuse of analgesics, as well as evaluation of analgesics abuse is needed in adolescent at suicide-risk.

A notable result was that adolescents had more attempted joint suicide than adults. In particular, the difference was significant only among female adolescents. Previous research reported that contagious nature of self-harm appears in young adults, especially in female adolescents [32]. Contagion in suicidal behavior has been explained as being caused by assortative selection of peer group or shared relationship stress [32, 33]. In our study, by similar mechanisms, it is estimated that female adolescents' joint suicides were reported more commonly. Female has a higher empathy for others than male [34]. So, we can consider the possibility that the motive was enhanced by others to attempt joint suicide or the suicidality was shared by vulnerable individuals in stressful state [33]. Furthermore, considering that most suicide attempters communicate their suicidal intentions prior to suicide, we should pay attention to suicidal communication before suicide [35]. Previous study had limits to identify the contagious nature of suicides at the school level. The results of this study provide more direct evidence to the hypothesis that adolescent suicides tend to be more contagious, since the results show that adolescents try to joint suicide attempt more than adults. However, researches on joint suicide are scarce, especially in studies aimed at adolescents. The study was conducted on patients visiting the ED only, so it was not clear whether adolescents attempted joint suicide more than adults. Although there is no significant difference between both groups, it is possible that the proportion of transfer to the ED after being rescued is relatively small because adults attempt suicide in a fatal method such as CO intoxication. Therefore, a study on the joint suicides of adolescents, especially of female, is needed in the future.

\section{Strengths and limitations}

This study has the benefit from a relatively large sample based on data collected from patients visiting the ED. Our study could supplement the limitations of representation in previous studies of inpatients.

However, this feature also acts as a limitation. Because patients are evaluated based on ED, it is often difficult to collect information with the patient at unconscious mental state or confusion, or with uncooperative patients. As a result, the major limitation is that the missing values are relatively high. To compensate for this, the same analysis was carried out with the complete date set and it was confirmed that there was not much difference in overall tendency. In addition, since it is a sample that has only been recruited from one hospital, a lack of demographic representation is also a limitation. Finally, 
because the analyses focused on adolescents versus one adult group, not different adult populations by age, the results have some limits, as it is difficult to identify the findings that were being influenced by a particular age group; thus, future studies will require more elaborate age-specific comparisons.

\section{Conclusions}

This study is the first direct comparison study of the socio-demographic, clinical, and suicide-related factors between adolescents and adults based on ED. Interpersonal problems are the main motivation for adolescent suicides, and previous suicide attempts were more frequent than adults. It also showed a tendency to attempt suicide with a lower intention to die and a relatively lesser degree of lethality than adults. Among them, taking analgesics is the most common method, so measures need to be taken against over-the-counter drug use by adolescents. Major depressive disorders were also the most common diagnosis, with adjustment disorders accounting for a significant proportion. Therefore, based on these results, there is an early need for therapeutic and social intervention to prevent adolescent suicide attempts. Our results highlight the importance of specific and individualized preventive strategies for adolescent suicide attempters. Moreover, careful assessment and appropriate treatment for underlying psychopathologies in suicide attempters among adolescents should be considered.

\section{Abbreviations \\ DSM-IV-TR: Diagnostic and Statistical Manual of Mental Disorders-IV-Text Revised; ED: Emergency Department; OECD: Organization for Economic Cooperation and Development; OR: Odds Ratio; WHO: World Health Organization}

\section{Acknowledgements}

We gratefully acknowledged the participation of the individuals involved in the study as well as the valuable and helpful comments of the editors and reviewers on this paper.

\section{Authors' contributions}

Study conception and design: MHK, JL, SM. Data collection, statistical expertise, analysis and interpretation of data: YSB, KH, YSC. Manuscript preparation, supervision, and critical revision of the paper: MHK, JL, YSB, JSA, ISP. All authors read and approved the final manuscript.

\section{Funding}

The authors did not receive any funding for this paper.

\section{Availability of data and materials}

The datasets used and analyzed during the current study are available from the corresponding author on reasonable request.

\section{Ethics approval and consent to participate}

This study was performed in accordance with ethical principles consistent with the Declaration of Helsinki, the International Conference on Harmonisation of Technical Requirements for Registration of Pharmaceuticals for Human Use and Good Clinical Practice. This study was approved by the Institutional Review Board of the Yonsei University Wonju College of Medicine (YWMR-15-9-097). Informed consent was waived due to the retrospective design of the study.
Consent for publication

Not applicable.

\section{Competing interests}

The authors declare that they have no competing interests.

\section{Author details}

${ }^{1}$ Department of Psychiatry, Yonsei University Wonju College of Medicine, 20 Ilsan-ro, Wonju 26426, Republic of Korea. ${ }^{2}$ Department of Emergency Medicine, Yonsei University Wonju College of Medicine, Wonju, Republic of Korea. ${ }^{3}$ Yonsei Soul Psychiatric Clinic, Wonju, South Korea.

Received: 13 November 2018 Accepted: 15 July 2019

Published online: 26 July 2019

\section{References}

1. WHO: Suicide data. Accessed 20 August 2017. http://www.who.int/ mediacentre/factsheets/fs398/en/.

2. Nock MK, Borges G, Bromet EJ, Cha CB, Kessler RC, Lee S. Suicide and suicidal behavior. Epidemiol Rev. 2008:30:133-54.

3. OECD: Suicide rates (indicator). Accessed 10 August 2017. https://data.oecd. org/healthstat/suicide-rates.htm.

4. Statistics Korea: Causes of death statistics in 2015. http://kostat.go.kr/portal/ eng/surveyOutline/5/1/index.static. Accessed 8 Oct 2017.

5. Statistics Korea: Adolescent statistics in 2016. http://kostat.go.kr/portal/eng/ surveyOutline/8/1/index.static. Accessed 8 Oct 2017.

6. Park S, Cho SC, Kim BN, Kim JW, Yoo HJ, Hong JP. Increased use of lethal methods and annual increase of suicide rates in Korean adolescents: comparison with adolescents in the United States. J Child Psychol Psychiatry. 2014;55:258-63.

7. Patel V, Flisher AJ, Hetrick S, McGorry PJtL. Mental health of young people: a global public-health challenge. 2007;369(9569):1302-13.

8. Parellada M, Saiz P, Moreno D, Vidal J, Llorente C, Alvarez M, Garcia-Portilla $P$, Ruiz-Sancho A, Arango C, Bobes J. Is attempted suicide different in adolescent and adults? Psychiatry Res. 2008;157:131-7.

9. Kolves K, Leo DD. Child, adolescent and young adult suicides: a comparison based on the Queensland suicide registry. J Child Adolesc Behav. 2015;3:209.

10. Younes N, Chee CC, Turbelin C, Hanslik T, Passerieux C, Melchior M. Particular difficulties faced by GPs with young adults who will attempt suicide: a cross-sectional study. BMC Fam Pract. 2013;14:68.

11. Kawashima $Y$, Ito $T$, Narishige R, Saito T, Okubo Y. The characteristics of serious suicide attempters in Japanese adolescents--comparison study between adolescents and adults. BMC Psychiatry. 2012;12:191.

12. Hawton K, Saunders KE, O'Connor RC. Self-harm and suicide in adolescents. Lancet. 2012:379:2373-82.

13. Qin P, Agerbo E, Mortensen PB. Suicide risk in relation to socioeconomic, demographic, psychiatric, and familial factors: a national register-based study of all suicides in Denmark, 1981-1997. Am J Psychiatry. 2003;160:765-72.

14. Lewinsohn PM, Rohde P, Seeley JR. Adolescent suicidal ideation and attempts: prevalence, risk factors, and clinical implications. Clin Psychol. 1996:3:25-46.

15. Zanus C, Battistutta S, Aliverti R, Montico M, Cremaschi S, Ronfani L, Monasta L, Carrozzi M. Adolescent admissions to emergency departments for self-injurious thoughts and behaviors. PLoS One. 2017;12:e0170979.

16. Wiktorsson S, Runeson B, Skoog I, Ostling S, Waern M. Attempted suicide in the elderly: characteristics of suicide attempters 70 years and older and a general population comparison group. Am J Geriatr Psychiatry. 2010;18:57-67.

17. Rihmer Z, Belsõ N, Kiss K. Strategies for suicide prevention. Curr Opin Psychiatry. 2002;15:83-7.

18. Lee CA, Choi SC, Jung KY, Cho SH, Lim KY, Pai KS, Cho JP. Characteristics of patients who visit the emergency department with self-inflicted injury. J Korean Med Sci. 2012;27:307-12.

19. Doshi A, Boudreaux ED, Wang N, Pelletier AJ, Camargo CA Jr. National study of US emergency department visits for attempted suicide and self-inflicted injury, 1997-2001. Ann Emerg Med. 2005:46:369-75.

20. Jung JH, Kim DK, Jung JY, Lee JH, Kwak YH. Risk factors of discharged against medical advice among adolescents self-inflicted injury and attempted suicide in the Korean emergency department. J Korean Med Sci. 2015;30:1466-70. 
21. Hawton K, Bergen H, Waters K, Ness J, Cooper J, Steeg S, Kapur N Epidemiology and nature of self-harm in children and adolescents: findings from the multicentre study of self-harm in England. Eur Child Adolesc Psychiatry. 2012;21:369-77.

22. Hulten A, Jiang GX, Wasserman D, Hawton K, Hjelmeland H, De Leo D, Ostamo A, Salander-Renberg E, Schmidtke A. Repetition of attempted suicide among teenagers in Europe: frequency, timing and risk factors. Eur Child Adolesc Psychiatry. 2001;10:161-9.

23. Tejedor MC, Diaz A, Castillon JJ, Pericay JM. Attempted suicide: repetition and survival-findings of a follow-up study. Acta Psychiatr Scand. 1999;100:205-11.

24. Donaldson D, Spirito A, Esposito-Smythers C. Treatment for adolescents following a suicide attempt: results of a pilot trial. J Am Acad Child Adolesc Psychiatry. 2005:44:113-20.

25. Kapur N, Cooper J, King-Hele S, Webb R, Lawlor M, Rodway C, Appleby L. The repetition of suicidal behavior: a multicenter cohort study. J Clin Psychiatry. 2006;67:1599-609.

26. Steinman KJ. High school students' misuse of over-the-counter drugs: a population-based study in an urban county. J Adolesc Health. 2006;38:445-7.

27. Portzky G, Audenaert $\mathrm{K}$, van Heeringen $\mathrm{K}$. Adjustment disorder and the course of the suicidal process in adolescents. J Affect Disord. 2005;87:265-70.

28. Bennett DS, Ambrosini PJ, Kudes D, Metz C, Rabinovich H. Gender differences in adolescent depression: do symptoms differ for boys and girls? J Affect Disord. 2005;89:35-44.

29. Ferrer $L$, Kirchner $T$. Suicidal tendency in a sample of adolescent outpatients with adjustment disorder: gender differences. Compr Psychiatry. 2014;55:1342-9.

30. Hawton K, Townsend E, Deeks J, Appleby L, Gunnell D, Bennewith O, Cooper $\mathrm{J}$. Effects of legislation restricting pack sizes of paracetamol and salicylate on self poisoning in the United Kingdom: before and after study. BMJ. 2001;322:1203-7.

31. Boyd CJ, McCabe SE, Cranford JA, Young A. Adolescents' motivations to abuse prescription medications. Pediatrics. 2006;118:2472-80.

32. Hawton K, Harriss L, Rodham K. How adolescents who cut themselves differ from those who take overdoses. Eur Child Adolesc Psychiatry. 2010;19:513-23.

33. Joiner TE. Contagion of suicidal symptoms as a function of assortative relating and shared relationship stress in college roommates. J Adolesc. 2003;26:495-504

34. Stuijfzand S, De Wied M, Kempes M, Van de Graaff J, Branje S, Meeus W. Gender differences in empathic sadness towards persons of the sameversus other-sex during adolescence. Sex Roles. 2016;75:434-46.

35. Pompili M, Belvederi Murri M, Patti S, Innamorati M, Lester D, Girardi P, Amore M. The communication of suicidal intentions: a meta-analysis. Psychol Med. 2016;46:2239-53.

\section{Publisher's Note}

Springer Nature remains neutral with regard to jurisdictional claims in published maps and institutional affiliations.

Ready to submit your research? Choose BMC and benefit from:

- fast, convenient online submission

- thorough peer review by experienced researchers in your field

- rapid publication on acceptance

- support for research data, including large and complex data types

- gold Open Access which fosters wider collaboration and increased citations

- maximum visibility for your research: over $100 \mathrm{M}$ website views per year

At $\mathrm{BMC}$, research is always in progress.

Learn more biomedcentral.com/submissions 